\title{
FCTC IMPLEMENTATION: THE ROLE OF STATE OR NON-GOVERNMENT ORGANIZATIONS? AN EXAMPLE OF THE CZECH REPUBLIC
}

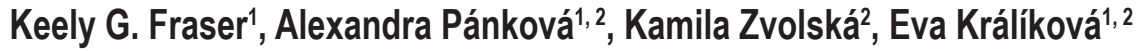 \\ ${ }^{1}$ Institute of Hygiene and Epidemiology, First Faculty of Medicine, Charles University and General University Hospital, Prague, Czech Republic \\ ${ }^{2}$ Centre for Tobacco-Dependent, 3rd Medical Department, Department of Endocrinology and Metabolism, First Faculty of Medicine, Charles \\ University and General University Hospital, Prague, Czech Republic
}

\section{SUMMARY}

Objectives: Smoking is the leading cause of premature mortality and morbidity. The aim of this study was to provide the first national description of organizational capacity and involvement in tobacco control (TC) measures outlined by the WHO Framework Convention on Tobacco Control (FCTC) within the Czech Republic.

Methods: Data were collected in a national cross-sectional survey of all 14 organizations engaged in TC activities within the Czech Republic. Organizational capacity (defined as skills, supports, partnerships, resources, and leadership) to implement TC activities, and level of involvement in key FCTC measures were assessed and compared across organizations.

Results: Despite the high economic costs of tobacco use, few organizations were involved in TC activities. $50 \%$ of all organizations involved in TC activities were non-government or non-profit organizations. Less than one third of organizations reported having a sufficient number of staff or adequate funding to work effectively. Skills for chronic disease prevention (CDP) practice including assessment, identifying relevant practices, developing and implementing initiatives were rated more favourably than skills to evaluate these activities. Level of involvement was ranked highest for activities that focused on creation of smoke-free environments and lowest for activities that focused on raising taxes and sales to minors. Organizations tended to be more involved in individual, rather than population-level prevention strategies. Inadequate funding, insufficient number of staff dedicated to working on TC, and lack of political will were major barriers.

Conclusions: This paper provides the first national description of organizational capacity and level of involvement in FCTC measures within the Czech Republic.

Key words: FCTC, tobacco control, capacity assessment, smoking, public health

Address for correspondence: K. G. Fraser, Institute of Hygiene and Epidemiology, First Faculty of Medicine, Charles University and General University Hospital, Studničkova 7, 12800 Prague 2, Czech Republic. E-mail: KeelyFraser@gmail.com

https://doi.org/10.21101/cejph.a5796

\section{INTRODUCTION}

Tobacco use is the leading cause of preventable death, disease and impoverishment globally (1). According to the World Health Organization (WHO), Europe has the highest prevalence of tobacco smoking among adults (28\%) and among the highest prevalence of tobacco use by adolescents (2). In the Czech Republic, tobacco consumption ranks about $25 \%$ in the population aged 15-65 years, and tobacco control (TC) measures rank among the poorest globally (3-5). Among all tobacco related chronic diseases, smoking is responsible for one in every six deaths in the Czech Republic (6). The burden of tobacco use on the Czech healthcare system and other tobacco-related costs call for growing urgency to invest in evidence-based measures that will decrease the demand for tobacco (7).

Tobacco use is a complex societal problem, influenced by an array of factors - many of which lie outside the influence of the health sector. TC requires comprehensive and integrated action across sectors to improve coherence, effectiveness and efficiency of policies (8-9). The WHO Framework Convention on Tobacco Control (FCTC) and its guidelines provide the foundation for countries to implement and manage tobacco control (10). The FCTC outlines six evidence-based measures that are best buy interventions, proven to reduce the demand for tobacco (11). These measures are referred to collectively by the acronym MPOWER which stands for Monitor tobacco use and prevention policies, Protect people from tobacco smoke, Offer help to quit tobacco use, Warn about the dangers of tobacco, Enforce bans on tobacco advertising, promotion and sponsorship, and Raise taxes on tobacco (11).

In order to work effectively on TC related activities outlined by the FCTC, organizations must have the capacity to do so, in terms of resources, skills, leadership and supports. Within the Czech Republic, little is known about what types of organizations are involved in tobacco control; the capacity these organizations may have in terms of structures, supports, resources and skills to work on TC related activities or; their level of involvement in evidenced based TC activities. 
Given the Czech Republic's history of weak TC, our aim was to conduct a capacity assessment to better understand the strengths and limitations of current TC efforts as they relate to the FCTC $(4,11)$. We conducted a cross sectional survey of all known organizations $(\mathrm{N}=20)$ involved in activities that address tobacco use. Our findings describe key determinants of organizational capacity including organizational supports, partnerships, resources, leadership, and chronic disease preveniton (CDP) skills to carry out TC activities. We also examined organizations level of involvement across settings, strategies used, and their level of involvement in MPOWER measures. Our findings provide data, which identifies strengths and gaps in organizational capacity, and provide an evidence base to help guide decision makers to identify strategic priorities. To our knowledge, this is the first national survey of organizational capacity and involvement in the Czech Republic, focused specifically on TC.

\section{MATERIALS AND METHODS}

Between June and November 2017, cross-sectional data were collected in a survey of all organizations in the Czech Republic that fit our inclusion criteria. Our inclusion criterion was that organizations must be engaged in primary or secondary prevention activities relating to $\mathrm{TC}$ at a national level, in the three years prior to data collection. Organizations were first identified by local TC experts, and then through an exhaustive Internet search using purposive sampling. Organizations included government ministries, offices and departments, public health organizations clinics, centres and commissions, herein referred to collectively as government organizations (GOV), non-government and nonprofit organizations, alliances, networks, professional associations and societies, and health agencies, herein referred to collectively as non-government organizations (NGO).

Prior to data collection, key informants with an in-depth knowledge of TC in the Czech Republic validated the final list of organizations to be included in the study. A total of 20 organizations fit our inclusion criteria. This represented a complete census of all known organizations engaged in primary or secondary prevention of tobacco use in the Czech Republic at a national level. We excluded any organizations that operated at a regional or community level only, as well as primary care facilities such as hospitals that focus mainly on tertiary prevention.

In this study, organizational capacity was conceptualized to include leadership, supports, skills, partnerships and resources. Tobacco related activities were defined as any programmes, policies, strategies, initiatives, or interventions that focus on reducing the demand for tobacco. Our survey tool was developed based on a comprehensive review of peer-reviewed literature and published reports of organizational capacity for CDP and healthy lifestyle promotion (12-15). Survey questions were drawn from a psychometrically sound scale developed by Hanusaik et al. (16) to measure determinants of organizational capacity for CDP, and adapted to focus specifically on TC related activities. Four internationally recognized TC experts helped established face validity of the questionnaire. The final working version of the survey was pilot tested with public health practitioners working in TC in three district health authorities in Nova Scotia, Canada.
The final version of the questionnaire consisted of 25 questions. The questionnaire gathered information about organizational characteristics and supports of capacity (leadership, skills resources and partnerships). We asked organizations to rate their skill level for core CDP skills including assessment, identification of relevant practices, development of action plans, implementation of activities, and evaluation. We also gathered data on level of involvement in population and individual intervention strategies, MPOWER measures, involvement across settings, and barriers faced by organizations. Most response sets were five-point Likert scales, with level of agreement response formats ranging from 1 (very low/strongly disagree) to 5 (very high/strongly agree).

A certified Czech translator translated the questionnaire from English to Czech. Researchers at the Centre for Tobacco-Dependent at Charles University and the General University Hospital in Prague reviewed the questionnaire to ensure cross-cultural adaptation of all questions.

Organizations were initially contacted by email to solicit their participation in the study. A Czech-speaking interviewer followed up with each organization by phone or email, to confirm their participation and to set a date for data collection. One key informant per organization completed the survey. The survey respondent was identified by the head of the organization as most knowledgeable about the organization's TC related activities. One survey was completed by each organization; with exception of two GOV organizations that worked closely on tobacco related activities and requested to complete one survey together. These two organizations were counted as a single organization in the analysis. Any incomplete data or inconsistencies were resolved with a follow up telephone call or e-mails.

\section{Statistical Analyses}

Since this study reports data collected in all organizations involved in TC at a national level (not a sample), significance testing was not relevant. Data analyses were conducted using IBM SPSS Statistics software, version 25.

\section{Ethical Approval}

The study received ethical approval from the General University Hospital in Prague (Study no. 39/16 S-IV). The head of each organization, as well as the survey respondent, provided written consent to participate in the study.

\section{RESULTS}

A total of 20 organizations met the inclusion criteria for the study. These organizations represented a complete census of all known organizations actively engaged in TC activities, at a national level in the Czech Republic in the three years prior to data collection. All eligible organizations were invited to participate in the study. Fourteen organizations agreed to take part in the study.

Our final census included an equal number of GOV $(n=7)$ and NGO $(n=7)$ organizations. Organizational characteristics are presented in Table 1. Overall organizations tended to rate their level of involvement in TC related activities as 'high' and TC was rated as a 'moderate' to 'very high' priority for all organizations. 
Table 1. Characteristics of organizations involved in TC related activities in the Czech Republic according to type of organization $(N=14)$

\begin{tabular}{|c|c|c|c|}
\hline & \multicolumn{3}{|c|}{ Type of organization ${ }^{\mathrm{a}}$} \\
\hline & $\begin{array}{c}\text { Total } \\
\mathrm{N}=14\end{array}$ & $\begin{array}{l}\text { GOV } \\
n=7\end{array}$ & $\begin{array}{l}\text { NGO } \\
n=7\end{array}$ \\
\hline \multicolumn{4}{|l|}{ Size, median (range) } \\
\hline Number of FTEs employed by organization ${ }^{b}$ & $2(0-5,000)$ & $651(23-5,000)$ & $0(0-2)$ \\
\hline Number of individuals working on TC within organization ${ }^{c}$ & $7.5(0-25)$ & $10(0-25)$ & $4(1-12)$ \\
\hline Number of FTEs work on TC within organization & $0(0-5)$ & $0(0-5)$ & 0 \\
\hline \multicolumn{4}{|l|}{ Target population served by organizations } \\
\hline Organizations that served general population ${ }^{d}, \%$ & 71.4 & 71.4 & 71.4 \\
\hline Organizations that served specific subpopulatione, $\%$ & 28.6 & 28.6 & 28.6 \\
\hline Organization's level of involvement in $\mathrm{TC}^{\mathrm{f}}$, mean (SD) & $4.0(1.1)$ & $3.7(1.4)$ & $4.3(0.7)$ \\
\hline TC's level of priority for the organization', mean (SD) & $4.5(0.7)$ & $4.3(0.9)$ & $4.7(0.5)$ \\
\hline
\end{tabular}

aGOV - government ministries, offices and departments, public health organizations, clinics, centres and commissions; NGO - non-government and non-profit organizations, alliances, networks, professional associations and societies, and health agencies

${ }^{\mathrm{b} F T E s}$ - full-time equivalents (paid employees)

'TC - tobacco control. This includes paid or unpaid individuals working full time or part time.

'Organizations whose TC activities mainly serve general population.

eOrganizations whose TC activities mainly serve specific subpopulations (e.g., health care professionals, individuals with mental illness, or those with substance abuse problems.

ffive-point Likert scale: 1 - very low; 2 - low; 3 - moderate; 4 - high; 5 - very high

Table 2. Levels of determinants (organizational supports, partnerships, financial resources) of organizational capacity for FCTC related activities in the Czech Republic according to type of organization $(N=14)$

\begin{tabular}{|c|c|c|c|}
\hline & \multicolumn{3}{|c|}{ Type of organization } \\
\hline & $\begin{array}{c}\text { Total } \\
\mathrm{N}=14\end{array}$ & $\begin{array}{l}\text { GOV } \\
n=7\end{array}$ & $\begin{array}{l}\text { NGO } \\
n=7\end{array}$ \\
\hline \multicolumn{4}{|l|}{ Organizational supports to guide TC activities, mean (SD) ${ }^{a}$} \\
\hline Strategic priorities & $3.9(1.1)$ & $3.9(1.2)$ & $4.0(0.9)$ \\
\hline Leadership & $4.0(0.9)$ & $4.0(1.1)$ & $4.0(0.8)$ \\
\hline Managerial & $4.1(0.6)$ & $4.3(0.5)$ & $4.0(0.8)$ \\
\hline Professional development opportunities & $3.9(0.7)$ & $4.1(0.6)$ & $3.7(0.7)$ \\
\hline Adequate number of staff & $2.4(1.2)$ & $2.7(1.3)$ & $2.0(0.9)$ \\
\hline Specialized knowledge and skills & $3.6(0.6)$ & $3.7(0.7)$ & $3.4(0.5)$ \\
\hline Equipment and tools & $3.4(0.9)$ & $4.0(0.8)$ & $2.9(0.6)$ \\
\hline \multicolumn{4}{|l|}{ Partnerships } \\
\hline Organizations that had formed partnerships, $\%$ & 64.3 & 57.1 & 71.4 \\
\hline Partnership effectiveness ${ }^{a}$, mean (SD) & $3.5(1.0)$ & $3.7(0.9)$ & $3.4(1.0)$ \\
\hline Partnerships formed across sectors ${ }^{a}$, mean (SD) & $2.9(1.1)$ & $3.0(1.2)$ & $2.9(1.0)$ \\
\hline \multicolumn{4}{|l|}{ Financial resources } \\
\hline Funding adequacy ${ }^{b}$, mean (SD) & $1.8(0.7)$ & $2.0(0.5)$ & $1.5(0.8)$ \\
\hline Funding stabilityc, mean (SD) & $2.5(1.3)$ & $3.1(1.2)$ & $1.6(0.8)$ \\
\hline Availability of external funding sources ${ }^{\mathrm{a}}$, mean (SD) & $2.1(1.3)$ & $2.3(1.6)$ & $1.8(0.9)$ \\
\hline
\end{tabular}

aScored on a five-point Likert scale: 1 - totally or strongly disagree; 2 - disagree; 3 - neither agree nor disagree; 4 - agree; 5 - totally or strongly agree

bScored on a five-point Likert scale: 1 - much less than adequate; 2 - less than adequate; 3 - neutral; 4 - adequate; 5 - more than adequate

'Scored on a five-point Likert scale: 1 - very unstable; 2 - somewhat unstable; 3 - stable; 4 - somewhat stable; 5 - very stable

Organizational capacity for involvement in FCTC measures was conceptualized to include leadership, supports, skills, partnerships and resources (Table 2). Among the indicators for internal organizational supports, strategic priorities, leadership, managerial support, and professional development opportunities were rated relatively high. Only half of organizations reported confidence in their staff's knowledge and skills to work effectively on tobacco control-related issues. In terms of access to necessary equipment and tools (e.g., software, computers, literature, etc.), this was not reported as a major barrier, but NGO tended to rate this lower than GOV.

Partnerships were assessed as an indicator of external support for FCTC activities (Table 2). More than half of all organization had formed partnerships of some kind to work on TC related 
activities. Although, NGO tended to form more partnerships than GOV, partnership effectiveness was rated slightly lower. Formation of cross sector partnerships was rated very low by all organizations.

The majority of organizations rated their funding to support TC activities as 'less than adequate' or 'much less than adequate'. Funding stability was rated lower by NGO than GOV. Availability of external sources of funding to support TC related activities was rated low by all organizations.

CDP practice skills including assessment, identifying relevant practices, developing and implementing initiatives were rated more favourably than skills to evaluate these activities (Table 3 ). Only half of all organizations reported confidence in their skills to evaluate the impact of their TC work.

Among all organizations, involvement in TC activities was highest in government settings, followed by healthcare settings. NGO reported greater involvement in these settings, compared to GOV. Few organizations were involved in TC activities in workplaces or schools, with the lowest level of involvement in the community at large.

Overall, organizations reported the highest level of involvement in individual-level strategies focused on public education to raise awareness. Less than half of all organizations were 'very involved' in population-level strategies, such as policy development, advocacy and creation of healthy environments.

Level of involvement in MPOWER measures was highest for activities that focused on creation of smoke-free workplaces and public places, followed by health information and warnings on packages, and monitoring of tobacco use (Table 4). Half of all organizations reported that they were 'very involved' in activities that focused on helping smokers to quit. Organizations reported the lowest level of involvement in MPOWER measures that focused on raising taxes, enforcing bans on tobacco advertising, promotion and sponsorship, and sales to minors.

Organizations reported a range of barriers (Table 4). Insufficient funding, inadequate number of staff dedicated to working on TC, lack of political will and competing priorities, as well as strong interference from the tobacco industry were reported as major barriers.

\section{DISCUSSION}

To our knowledge, this is the first national survey of organizational capacity and level of involvement in FCTC measures among organizations in the Czech Republic. Our findings show that

Table 3. Skill level for core chronic disease prevention practices to address tobacco use, levels of involvement in specific settings, and intervention strategies used according to type of organization $(N=14)$

\begin{tabular}{|c|c|c|c|}
\hline & \multicolumn{3}{|c|}{ Type of organization } \\
\hline & $\begin{array}{c}\text { Total } \\
\mathrm{N}=14\end{array}$ & $\begin{array}{l}\text { GOV } \\
n=7\end{array}$ & $\begin{array}{l}\text { NGO } \\
n=7\end{array}$ \\
\hline \multicolumn{4}{|c|}{ Core CDP practice skills specific to tobacco control activitiesa, mean (SD) } \\
\hline Assessment & $3.8(1.4)$ & $4.1(1.4)$ & $3.2(1.3)$ \\
\hline Identifying relevant practices & $3.9(1.3)$ & $3.3(1.6)$ & $4.4(0.5)$ \\
\hline Developing action plans & $4.1(1.1)$ & $4.0(1.4)$ & $4.2(0.7)$ \\
\hline Implementation of activities & $4.2(1.1)$ & $4.0(1.4)$ & $4.4(0.5)$ \\
\hline Evaluation & $3.1(1.4)$ & $3.2(1.3)$ & $3.0(1.5)$ \\
\hline \multicolumn{4}{|l|}{ Level of involvement in specific settings ${ }^{b}$, mean (SD) } \\
\hline Schools & $2.1(1.3)$ & $2.6(1.3)$ & $1.7(1.2)$ \\
\hline Workplaces & $2.6(1.4)$ & $2.9(1.6)$ & $2.4(1.3)$ \\
\hline Health care & $3.3(1.4)$ & $3.1(1.6)$ & $3.4(1.2)$ \\
\hline Community at large & $2.1(1.0)$ & $2.1(1.1)$ & $2.1(0.8)$ \\
\hline Government settings & $3.5(1.5)$ & $3.1(1.5)$ & $3.9(1.4)$ \\
\hline \multicolumn{4}{|c|}{ Level of involvement in intervention strategies targeting individual levelc ${ }^{c}$, mean (SD) } \\
\hline Public education & $2.7(0.6)$ & $2.6(0.7)$ & $2.9(0.3)$ \\
\hline Programmes to build skills at individual level & $2.3(0.8)$ & $2.3(0.9)$ & $2.3(0.7)$ \\
\hline Service provider skill building & $2.3(0.8)$ & $2.2(0.9)$ & $2.4(0.7)$ \\
\hline Clinical interventions and treatment of individuals & $2.3(0.8)$ & $2.2(1.0)$ & $2.3(0.7)$ \\
\hline \multicolumn{4}{|c|}{ Level of involvement in intervention strategies targeting population levele ${ }^{c}$, mean (SD) } \\
\hline Public policy change and advocacy & $2.4(0.8)$ & $2.5(0.8)$ & $2.2(0.7)$ \\
\hline Creating healthy environments & $2.4(0.6)$ & $2.4(0.7)$ & $2.4(0.5)$ \\
\hline
\end{tabular}

aScored on a 5-point Likert scale: 1 - poor; 2 - fair; 3 - moderate; 4 - good; 5 - very good. Response categories "not our role" and "don't know" were also included as options. In these cases organizations were excluded from the calculated mean.

'Scored on a 5-point Likert scale: 1 - very low; 2 - low; 3 - moderate; 4 - high; 5 - very high. Response categories "don't know" and "not involved" were also options. In these cases, the response was classified as $1-$ very low.

"Scored on a 3-point scale: 1 - not at all involved; 2 - somewhat involved; 3 - very involved. Response category "don't know" was also included as option. In these cases the response was excluded from the calculated mean. 
Table 4. Level of involvement in MPOWER measures and barriers faced according to type of organization $(N=14)$

\begin{tabular}{|c|c|c|c|}
\hline & $\begin{array}{c}\text { Total } \\
\mathrm{N}=14\end{array}$ & $\begin{array}{l}\text { GOV } \\
n=7\end{array}$ & $\begin{array}{l}N G O \\
n=7\end{array}$ \\
\hline \multicolumn{4}{|l|}{ Level of involvement in MPOWER measuresa mean (SD) } \\
\hline Raise taxes on tobacco & $2.0(0.8)$ & $2.0(0.8)$ & $2.0(0.8)$ \\
\hline Smoke-free workplaces and public places & $2.7(0.6)$ & $2.6(0.7)$ & $2.9(0.3)$ \\
\hline Health information and warnings on tobacco packages & $2.4(0.8)$ & $2.6(0.7)$ & $2.3(0.9)$ \\
\hline Enforce bans on tobacco advertising, promotion and sponsorship & $2.1(0.8)$ & $2.2(0.9)$ & $2.0(0.8)$ \\
\hline Monitor tobacco use & $2.4(0.9)$ & $2.7(0.7)$ & $2.0(0.9)$ \\
\hline Offering smokers help to quit tobacco use & $2.2(0.9)$ & $2.3(0.9)$ & $2.1(0.8)$ \\
\hline Sales to minors & $1.8(0.8)$ & $2.3(0.7)$ & $1.3(0.5)$ \\
\hline \multicolumn{4}{|l|}{ Barriers, $\%$} \\
\hline Insufficient funding & 57.1 & 57.1 & 57.1 \\
\hline Insufficient number of staff & 57.1 & 71.4 & 42.9 \\
\hline Lack of political will or competing priorities & 42.9 & 57.1 & 28.6 \\
\hline Tobacco industry interference & 28.6 & 28.6 & 28.6 \\
\hline
\end{tabular}

aScored on a 3-point Likert scale 1 - not at all involved; 2 - somewhat involved; 3 - very involved. Response category "don't know" was also included as option. In these cases the response was excluded from the calculated mean.

despite the high economic costs of tobacco use, few organizations were involved in key evidence-based tobacco control measures as outlined by the FCTC. TC activities were underfunded and most organizations did not have sufficient human resources dedicated to working on TC to achieve their objective. Furthermore, many Czech organizations were highly involved in intervention strategies that focus too far downstream to have any real impact on population health outcomes (17).

In terms of organizational supports, most organizations had strategic priorities and good leadership to guide their TC related work. Professional development opportunities were available, but less so to NGO. Less than one third of organizations had a sufficient number of staff dedicated to working on TC related activities and many did not have the proper equipment or tools (e.g., software, computers, literature, etc.) to work effectively. In addition to developing a critical mass of professionals dedicated to working on tobacco control, there is also a need to invest in helping these professionals to develop the specialized skills, knowledge, and tools to support evidence-based practices and policy decisions relating to tobacco control (18).

\section{Partnerships}

More than half of all organizations had formed partnerships to work on TC activities, but cross-sector partnerships were less common. Because tobacco use is a complex societal problem, and smoking rates are determined by an array of factors - many of which lie outside the influence of the health sector, diverse multi-sectorial partnerships are key to achieving better outcomes. Diversity improves collective understanding and problem solving capacities (19). Our findings suggest that greater cooperation within and across sectors is needed within the Czech TC community in order to effectively implement FCTC measures. Success stories of partnership and collaboration in other countries provide an excellent example of how organizations can engage, share resources and enhance knowledge exchange to build capacity and advance the national TC agenda (20).

\section{Resources}

Despite TC being rated as a 'high' or 'very high' priority for most organizations, funding adequacy for TC related activities was rated low by GOV and even lower by NGO. Our findings are similar to those reported by global survey findings, which showed that despite being a high priority, less than $40 \%$ of countries ( $n=65$ out of 167) had allocated a specific budget for prevention and control of non-communicable disease (21). The availability of external sources of funding to support TC activities was rated very low by all organizations. Inadequate funding for TC related activities may be a reflection of chronic underfunding of the healthcare system as a whole. In the Czech Republic, the healthcare system has undergone major restructuring since the end of communism in 1989 (22). Health expenditure accounts for $7.2 \%$ of the country's GDP, but it is not known how much of this is allocated to specifically to health promotion and CDP activities that focus on TC (23). The country's high smoking rates, which increased between 2000-2011, and the high incidence of smoking related diseases (23) provide evidence that CDP efforts are under-resourced and/or may be focused too far downstream to have any real impact on population health.

\section{Core Chronic Disease Prevention Skills}

In terms of core CDP practices, evaluation skills were rated low by all organizations. Evaluation is critical to building an evidence base to inform best practices in CDP programming (24). Our findings provide evidence that organizations must put a greater emphasis on the importance of evaluation by dedicated more resources to evaluation activities and offering training in evaluation methodology. In Canada, Hanusaik et al. (16) similarly found that compared to other core CDP skills, evaluation skills were consistently rated as low among organizations engaged in CDP.

\section{Intervention Strategies}

Overall, organizations reported the highest level of involvement in individual-level strategies focused on public education 
to raise awareness. Although strategies targeting individuals are important, these activities tend to be resource intensive and have limited impact on population health, largely because they depend on long term individual behavioural change (17).

In general, population-level strategies require less individual effort, and have the greatest impact on population health outcomes (17). For example, policies supporting smoke free public spaces change the environmental context to make breathing clean air the default choice, regardless of an individual's level of education, income, access to health care, or other societal factors. An individual would have to expend significant effort to not benefit from a cleaner air policy. Population level strategies improve not only individual health, but also have economic benefits by reducing healthcare spending and mitigating productivity losses (17). Less than half of all Czech organizations reported that they were 'very involved' in population-level strategies to address tobacco use.

\section{Level of Involvement in MPOWER Measures}

Evidence-based MPOWER measures outlined by the FCTC are inexpensive for countries to implement and they work (11). Czech organizations reported the highest level of involvement in measures that focused on protection from exposure to tobacco smoke through creation of smoke free workplaces and public spaces, followed by warning about the dangers of tobacco, and monitoring tobacco use. Organizations reported the lowest levels of involvement for activities that focus on sales to minors and raising taxes. Of all the MPOWER measures, increasing price through higher taxes is the single most effective way to encourage tobacco users to quit and prevent children from starting to smoke (25). Of all European countries, the Czech Republic has among the lowest cigarette prices, due to low excise taxes (26-27). While low cigarette prices decrease the demand for illegal or contraband cigarettes, cheaper prices are associated with high smoking rates, and greater uptake among youth. Higher cigarette prices are particularly effective in encouraging cessation and motivate smokers to quit, particularly young people and those living in poverty (26-28). Over time, simple and effectively implemented tax structures decrease tobacco consumption (25). Individuals living in poverty experience the greatest health disparities (29). Higher tobacco taxes help decrease health disparities and improves families' health, productivity and wage earning capacity by decreasing smoking related illness and death (25).

\section{Barriers to Working on Tobacco Control}

More than half of all organizations reported that insufficient funding and inadequate number of staff dedicated to working on TC as major barriers. Lack of political will and competing priorities, as well as interference from the tobacco industry were all named as major barriers. Our findings support previously published reports, which showed that the tobacco industry enjoys a high-level of political support in the Czech Republic and continues to actively influence TC policies (30).

\section{Limitations}

This study has several limitations. One limitation is that data were collected from one respondent per organization. Although respondents were carefully selected by the head of each organization and confirmed to be the most knowledgeable about the organization's TC related activities, responses are inevitably influenced by individual's views and experiences. Furthermore, there are no gold standard measures of organizational capacity. Ideally organizational level constructs such as leadership, supports, partnership effectiveness, resources and skills should be assessed using objective measures. However, within the domain of organizational research, self-report is the most common method of data collection. While cross sectional data are helpful in identifying strengths and gaps in organizational capacity and provide a snapshot of organizations' involvement in TC activities, longitudinal data are needed to establish any causal associations. Future research should focus on the association between organizational capacity and level of TC nationally, as well as the association with the prevalence of smoking over time. Another limitation of this study is that we did not ask organizations about facilitators to working on TC related activities. In terms of facilitators, intangible outcomes such as trust, mutual respect, transparency, resource sharing and synergy that may emerge when organizations work together are valuable assets, which contribute to organizational capacity but are difficult to measure. Finally, the extent to which these findings are generalizable to other risk factors for chronic disease, such as physical activity, healthy eating or alcohol abuse is not known.

\section{CONCLUSION}

In conclusion, this paper provides the first national description of organizational capacity and involvement in FCTC measures within the Czech Republic. Our data identify areas of TC that need improvement including the need for increased funding and resources dedicated to TC activities, as well as a need for increased involvement in population-level strategies and cross sector collaboration. These findings provide empirical evidence to local decision makers that may inform strategic priorities and help move the TC agenda forward in the Czech Republic.

\section{Adherence to Ethical Standards}

The study received ethical approval from the General University Hospital in Prague (Study no. 39/16 S-IV).

\section{Funding}

This project was supported by funding from Charles University (PROGRES Q25/LF1).

\section{Conflict of Interests}

None declared

\section{REFERENCES}

1. World Health Organization. WHO report on the global tobacco epidemic, 2015: raising taxes on tobacco. Geneva: WHO; 2015.

2. World Health Organization. Data and statistics [Internet]. Geneva: WHO; 2019 [cited 2019 Aug 30]. Available from: http://www.euro.who.int/en/ health-topics/disease-prevention/tobacco/data-and-statistics.

3. Váňová A, Skývová M, Malý M. Tobacco abuse in the Czech Republic in 2017. Prague: NIPH; 2018.

4. Joossens L, Raw M. The Tobacco Control Scale 2013 in Europe. Brussels: ECL; 2014. 
5. American Cancer Society; Vital Strategies. Czech Republic: fact sheet [Internet]. ACS; 2019 [cited 2019 Aug 30]. Available from: https://tobaccoatlas.org/wp-content/uploads/pdf/czech-republic-country-facts.pdf.

6. Peto R, Lopez AD, Pan H, Boreham J, Thun M. Mortality from smoking in developed countries 1950-2020 [Internet]. 2015 [cited 2019 Aug 30]. Available from: http://gas.ctsu.ox.ac.uk/tobacco/C0002.pdf.

7. Organization for Economic Co-operation and Development. Caring for quality in health: lessons learnt from 15 reviews of health care quality. Paris: OECD; 2017.

8. World Health Organization. Framework for country action across sector for health and health equity: WHO Discussion Paper [Internet]. Geneva: WHO; 2014 [cited 2014 Oct 29]. Available from: http://www.who.int/ $\mathrm{nmh} /$ events/framework-discussion-paper-rev.pdf.

9. Christensen T, Lægreid P, editors. Autonomy and regulation: coping with agencies in the modern state. Cheltenham: Edward Elgar Publishing; 2006.

10. World Health Organization. WHO Framework Convention on Tobacco Control. Geneva: WHO; 2003.

11. World Health Organization. WHO Report on the Global Tobacco Epidemic, 2008: the MPOWER package. Geneva: WHO; 2008.

12. Smith C, Raine K, Anderson D, Dyck R, Plotnikoff R, Ness K, et al. A preliminary examination of organizational capacity for heart health promotion in Alberta's regional health authorities. Promot Educ. 2001;Supp 1:40-3.

13. McLean S, Ebbesen L, Green K, Reeder B, Butler-Jones D, Steer S. Capacity for community development: an approach to conceptualization and measurement. J Community Dev Soc. 2001;32(2):251-70.

14. Taylor SM, Elliott S, Riley B. Heart health promotion: predisposition, capacity and implementation in Ontario public health units, 1994-96. Can J Public Health. 1998;89(6):410-4.

15. Joffres C, Heath S, Farquharson J, Barkhouse K, Latter C, MacLean DR. Facilitators and challenges to organizational capacity building in heart health promotion. Qual Health Res. 2004;14(1):39-60.

16. Hanusaik N, O’Loughlin JL, Kishchuk N, Eyles J, Robinson K, Cameron R. Building the backbone for organisational research in public health systems: development of measures of organisational capacity for chronic disease prevention. J Epidemiol Community Health. 2007;61(8):742-9.

17. Frieden TR. A framework for public health action: the health impact pyramid. Am J Public Health. 2010 Apr;100(4):590-5.

18. Mereu A, Sotgiu A, Buja A, Casuccio A, Cecconi R, Fabiani L, et al. Professional competencies in health promotion and public health: what is common and what is specific? Review of the European debate and perspectives for professional development. Epidemiol Prev. 2015;39(4 Suppl 1):33-8

19. Page SE. The Difference: how the power of diversity creates better groups, firms, schools, and societies. Princeton: Princeton University Press; 2008.

20. McDonald PW, Viehbeck S. From evidence-based practice making to practice-based evidence making: creating communities of (research) and practice. Health Promot Pract. 2007 Apr;8(2):140-4.

21. World Health Organization. Assessment of national capacity for noncommunicable disease prevention and control: the report of a global survey. Geneva: WHO; 2001.

22. Kinkorová J, Topolčan O. Overview of healthcare system in the Czech Republic. EPMA J. 2012;3(1):4. doi: 10.1007/s13167-012-0139-9

23. OECD Reviews of Health Care Quality: Czech Republic 2014: raising standards [Internet]. Paris: OECD; 2014 [cited 2019 Aug 30]. Available from: http://dx.doi.org/10.1787/9789264208605-en.

24. Milstein B, Chapel TJ, Wetterhall SF, Cotton DA. Building capacity for program evaluation at the Centers for Disease Control and Prevention. N Direct Eval. 2002;(93):27-46.

25. World Health Organization. Raise taxes on tobacco [Internet]. Geneva: WHO; 2008 [cited 2019 Aug 30]. Available from: https:/www.who.int/ tobacco/mpower/publications/en tfi mpower brochure r.pdf?ua=1

26. Ross H, Blecher E, Yan L, Hyland A. Do cigarette prices motivate smokers to quit? New evidence from the ITC survey. Addiction. 2011 Mar;106(3):609-19.

27. Statista. Retail price of a premium pack of 20 cigarettes in selected European countries in 2017 (in GBP) [Internet]. Hamburg: Consumer Goods \& FMCG [cited 2019 Aug 30]. Available from: https://www.statista.com/ statistics/415034/cigarette-prices-across-europe/.

28. World Health Organization. Tobacco [Internet]. Geneva: WHO; 2019 [cited 2018 Mar 9]. Available from: http://www.who.int/en/news-room/ fact-sheets/detail/tobacco.

29. Cheng TL, Johnson SB, Goodman E. Breaking the intergenerational cycle of disadvantage: the three generation approach. Pediatrics. 2016 Jun;137(6). doi: 10.1542/peds.2015-2467.

30. Shirane R, Smith K, Ross H, Silver KE, Williams S, Gilmore A. Tobacco industry manipulation of tobacco excise and tobacco advertising policies in the Czech Republic: an analysis of tobacco industry documents. PLoS Med. 2012;9(6):e1001248. doi: 10.1371/journal.pmed.1001248

Received April 23, 2019

Accepted in revised form August 30, 2019 